\title{
SYNDICATED LENDING IN THE LIST OF LEGAL MECHANISMS OF INNOVATIVE BUSINESS ACTIVITY
}

\author{
Olesya P. Kazachenok \\ Volgograd State University, Volgograd, Russian Federation
}

\begin{abstract}
Introduction. The present article is intended to facilitate the creation of an adequate system of legal regulation of innovative banking activities in conditions of necessity to organize processes of formation of a new type of national economy.

It is proved that the loan is one of the essential means of promoting the favorable development of innovative entrepreneurship, and legal structure of syndicated lending in favor primary legal mechanism for financing innovative projects expensive. Methods are used in combination - the methods of scientific knowledge, including basic methods of historicism, systematic analysis and comparative law. Results. In the context of legal research of innovative entrepreneurial activities of banks the author identified actions aimed at creating new or improved banking products, as well as the development and adaptation of different ways to improve the efficiency of the business activities of banks to achieve any economic or strategic effects in banking transactions and signing other transactions. The article examines the advantages and disadvantages of the syndicated loan, the demand for and the scope of applicability of this type of innovative banking products.

Studying the legal nature of the syndicated loan is complicated by the multiplicity of persons in the obligation and concluded between the members of the syndicate agreement. The problem of slow development of syndicated lending business entities in Russia is revealed. It is noted that these financial overseas technology is used with respect to a long and successful, and in the Russian syndicated lending is considered innovative banking products. It is concluded that this is due to lack of detailed legal regulation of this area of business relations, as well as poor development of mutual credit partnerships between commercial banks. The author identifies the gaps of the existing legal regulation, the removal of which will contribute to the development of syndicated lending to domestic borrowers and, as a consequence, the growth of the real sector of the national economy as a whole.

Key words: innovative entrepreneurship, entities of innovative entrepreneurship, legal regulation of banking activities, syndicate, consortium, agreement, syndicated loan, innovative banking product.
\end{abstract}

УДК 341.161

ББК 67.39

\section{СИНДИЦИРОВАННОЕ КРЕДИТОВАНИЕ В ПЕРЕЧНЕ ПРАВОВЫХ МЕХАНИЗМОВ РАЗВИТИЯ ИННОВАЦИОННОЙ ПРЕДПРИНИМАТЕЛЬСКОЙ ДЕЯТЕЛЬНОСТИ}

\author{
Олеся Павловна Казаченок \\ Волгоградский государственный университет, г. Волгоград, Российская Федерация
}


основное место занимают методы историзма, системности, анализа и сравнительно-правовой. Результаты: в контексте правового исследования инновационной предпринимательской деятельности банков выявляются мероприятия, направленные на создание нового или усовершенствованного банковского продукта, а также разработку и адаптацию различных способов повышения эффективности предпринимательской деятельности банков, ориентированных на достижение какого-либо экономического или стратегического эффекта при совершении банковских операций и заключении иных сделок. Обосновано значимое место синдицированного кредитования в перечне такого рода мероприятий. В статье исследуются преимущества и недостатки синдицированного кредитования, востребованность и сфера применимости данного вида инновационного банковского продукта.

Изучается правовая природа синдицированного кредита, осложненная множественностью лиц в обязательстве, а также заключаемого между членами синдиката соглашения. Исследуется проблема медленного развития синдицированного кредитования хозяйствующих субъектов в современной России. Отмечается, что за рубежом данная финансовая технология применяется относительно давно и успешно, а в Российской Федерации синдицированное кредитование считается инновационным банковским продуктом. Делается вывод, что такое положение обусловлено отсутствием детального правового регулирования данной области предпринимательских отношений, а также слабым развитием взаимного кредитного партнерства между коммерческими банками. Авторы выявляют пробелы действующего правового регулирования, устранение которых будет способствовать развитию синдицированного кредитования отечественных заемщиков и, как следствие, росту реального сектора национальной экономики в целом.

Ключевые слова: инновационная предпринимательская деятельность, субъекты инновационной предпринимательской деятельности, правовое регулирование банковской деятельности, синдикат, консорциум, соглашение, синдицированный кредит, инновационный банковский продукт.

\section{Введение}

Создание системы правового регулирования инновационной деятельности, способной упорядочить процессы совершенствования научной и технической базы страны с последующим выходом на мировой рынок высокотехнологичной продукции, а также обеспечить поддержку со стороны государства наукоемких сфер национальной экономики, необходимо с целью повышения экономического роста страны в целом [5, с. 136]. Обозначенные процессы требуют адекватного правового сопровождения.

Распоряжением Правительства РФ от 8 декабря 2011 г. утверждена Стратегия инновационного развития Российской Федерации на период до 2020 г. [9], которая задает долгосрочные ориентиры развития субъектам инновационной деятельности, в числе которых прежде всего органы государственной власти всех уровней, научно-исследовательский и предпринимательский сектор.

Важнейшими субъектами инновационной предпринимательской деятельности являются банки. Однако, к сожалению, на сегодняшний день не приходится говорить об их эффективном развитии как участников инновационной предпринимательской деятельности.
В условиях национального экономического и мирового финансового кризиса нельзя отрицать необходимость поступательного инновационного развития банковской системы России.

\section{Развитие}

\section{синдицированного кредитования на банковском рынке России}

Кредит выступает одним из необходимых средств, способствующих благоприятному развитию инновационной предпринимательской деятельности. При этом зачастую для финансирования инновационных проектов требуется достаточно крупная сумма (от 500 млн руб. и выше), которую один банк не в состоянии предоставить заемщику. В подобном случае для кредитования коммерческие банки объединяются в группу - синдикат (консорциум) и совместно предоставляют заемщику требующуюся сумму - синдицированный (консорциальный) кредит.

В международной практике синдицированное кредитование является достаточно распространенным явлением, в отличие от нашей страны, для которой данный правовой институт в полной мере еще не освоен законодателем. 
В настоящее время в России правовая регламентация синдицированного кредитования практически отсутствует [3; 4].

Решением данной проблемы является, на наш взгляд, закрепление специальной нормы в ГК РФ, посвященной синдицированному кредиту. Подобная инициатива уже имела место, однако ввиду того, что законопроект был не в полной мере проработан, содержал неоправданные ограничения для гражданского оборота, он не был внесен в Государственную Думу РФ [8].

В зарубежных странах существует законодательная база, направленная на урегулирование института синдицированного кредитования, а также разработанная Лондонской ассоциацией кредитного рынка (LMA) и повсеместно используемая на практике унифицированная форма договора синдицированного кредитования.

Длительное время в нашей стране отсутствовала стандартная документация по оформлению синдицированного кредита, что существенно затрудняло использование данной формы кредитования, в том числе для целей финансирования инноваций. Лишь в феврале 2015 г. Комитетом по синдицированному кредитованию Ассоциации региональных банков России была разработана и представлена стандартизированная документация по синдицированному кредитованию.

Использование в правоприменительной практике стандартизированной документации упростит порядок заключения договора о предоставлении синдицированного кредита, а также уменьшит правовые риски для сторон договора.

В условиях отсутствия полноценной нормативной базы, регламентирующей отношения, связанные с синдицированным кредитованием, в отечественной науке ведутся дискуссии о сущности и правовой природе договора синдицированного кредитования $[6$, с. 70 , 79], а также о наличии множественности лиц в обязательстве на стороне кредитора [7, c. 11, 69].

Развитие рынка синдицированного кредитования на текущем этапе развития экономики особенно важно для региональных банков и компаний, так как данный механизм имеет ряд преимуществ, по сравнению с обычными двусторонними займами, как для банка-кредитора, так и для заемщика.

Среди преимуществ синдицированного кредитования для хозяйствующего субъектазаемщика следует отметить возможность увеличения суммы кредита и сроков кредитования, упрощение процесса оформления кредита.

Наряду с очевидными преимуществами синдицированное кредитование имеет и некоторые недостатки, такие как предъявление особых требований к финансовому состоянию хозяйствующего субъекта-заемщика (обычно они фиксируются в договоре), а также наличие существенных ограничений, налагаемых на коммерческую деятельность заемщика [2].

Анализируя текущую ситуацию на российском рынке синдицированного кредитования, следует отметить, что основной проблемой в данной сфере является новизна синдицированного кредита как банковского продукта для российского рынка.

Следствиями правового вакуума, отсутствия общепринятой процедуры кредитования, единых критериев оценки заемщика / поручителя / гаранта, существующих рисков нарушения валютного законодательства являются нераспространенность данной формы кредитования и несформированность практики заключения подобных договоров в нашей стране, что приводит к тому, что большинство сделок оформляется с использованием регулирования на основе английского права.

\section{Выводы}

Проведенный анализ позволил сделать некоторые выводы:

Во-первых, в отличие от зарубежных стран, где преддоговорному этапу заключения основного договора синдицированного кредитования уделяется огромное внимание, российская практика, к сожалению, проводит подобную подготовку с меньшей тщательностью.

Во-вторых, процедура заключения договора синдицированного кредитования не урегулирована российским законодательством на должном уровне. Решением данной проблемы является внесение соответствующих изменений в отечественное законодательство с учетом опыта правового регулирования, суще- 
ствующего в европейских странах, в частности, в Великобритании.

В-третьих, очевидно, что институт синдицированного кредитования является финансовым инструментом, с помощью которого возможно решить проблемы, связанные с недостатком финансирования инновационных отраслей науки в нашей стране. Создание нормативной правовой базы для регламентации механизмов синдицированного кредитования инновационной деятельности расширит сферу его использования, а предоставление минимальных гарантий со стороны государства выступит фактором, снижающим риски сторон по сделке.

\section{СПИСОК ЛИТЕРАТУРЫ}

1. Белов, В. А. Гражданское право. Общая и Особенная части / В. А. Белов. - М. : ЦентрЮрИнфоР, 2008. $-792 \mathrm{c}$.

2. Заливако, А. Л. Структурирование отношений сторон в рамках договора синдицированного кредитования / А. Л. Заливако // ИА «Банкир.Ру». - Электрон. текстовые дан. - Режим доступа: http://bankir.ru/ publikacii/20110503/stryktyrirovanie-otnoshenii-storonv-ramkah-dogovora-sindicirovannogo-kreditovaniya9739171/ (дата обращения: 28.08.2016). - Загл. с экрана.

3. Заявление Правительства РФ № 1472п-П13, Банка России № 01-001/1280 от 5 апр. 2011 г. «О Стратегии развития банковского сектора Российской Федерации на период до 2015 года» // Вестник Банка России. -2011. - 20 апр. (№ 21).

4. Инструкция Банка России «Об обязательных нормативах банков» от 3 дек. 2012 г. № 139-И // Вестник Банка России. - 2012. - 21 дек. (№ 74).

5. Иншакова, А. О. О формировании нового арсенала методологии научных правовых исследований в сфере нанотехнологий и наноиндустрии / А. О. Иншакова, Д. П. Фролов // Вестник Пермского университета. Серия «Юридические науки». 2016. - № 2 (32). - C. 133-143.

6. Качалова, А. В. Правовые особенности заключения договоров о предоставлении синдицированных кредитов / А. В. Качалова // Законодательство. - 2006. - № 2. - С. 75-83.

7. Попкова, Л. А. Договор синдицированного кредита: правовая природа и содержание / Л. А. Попкова // Законы России. Опыт. Анализ. Практика. - 2016. - № 2. - С. 69-74.

8. Проект Федерального закона «О внесении изменений в главу 42 части второй Гражданского кодекса Российской Федерации и отдельные законодательные акты Российской Федерации» // Официальный сайт Минэкономразвития России. - Электрон. текстовые дан. - Режим доступа: http://economy.gov.ru/ minec/activity/sections/ria/anounce/20150604 (дата обращения: 18.09.2016). - Загл. с экрана.

9. Распоряжение Правительства РФ «Об утверждении Стратегии инновационного развития Российской Федерации на период до 2020 года» от 8 дек. 2011 г. № 2227-p // Собрание законодательства РФ. - 2012. -2 янв. - № 1. - Ст. 216.

10. Сапункова, А. И. Правовое регулирование синдицированного кредитования в международном коммерческом обороте : автореф. дис. ... канд. юрид. наук / Сапункова Анна Игоревна. - М., 2008. $32 \mathrm{c}$.

\section{REFERENCES}

1. Belov V.A. Grazhdanskoe pravo. Obshchaya $i$ Osobennaya chasti [Civil law. General and Special Parts]. Moscow, 2008. 792 p.

2. Zalivako A.L. Strukturirovanie otnosheniy storon $\mathrm{v}$ ramkakh dogovora sinditsirovannogo kreditovaniya [Structuring the relationship of the parties under the syndicated loan agreement]. IA "Bankir.Ru". Available at: http://bankir.ru/publikacii/ 20110503/stryktyrirovanie-otnoshenii-storon-vramkah-dogovora-sindicirovannogo-kreditovaniya9739171/. (accessed August 28, 2016).

3. Zayavlenie Pravitelstva RF № 1472p-P13, Banka Rossii № 01-001/1280 ot 5 apr. 2011 g. "O Strategii razvitiya bankovskogo sektora Rossiyskoy Federatsii na period do 2015 goda" [Statement by the Government of the Russian Federation no. 1472p-P13, Bank of Russia no. 01-001/ 1280 of April 5, 2011 "On the Development Strategy of the Russian banking sector for the period till 2015"]. Vestnik Banka Rossii, 2011, no. 21.

4. Instruktsiya Banka Rossii "Ob obyazatelnykh normativakh bankov" ot 3 dek. 2012 g. № 139-I [Instruction of Bank of Russia "On the Required Ratios of Banks" of December 3, 2012 no. 139-I]. Vestnik Banka Rossii, 2012, no. 74.

5. Inshakova A.O., Frolov D.P. O formirovanii novogo arsenala metodologii nauchnykh pravovykh issledovaniy v sfere nanotekhnologiy i nanoindustrii [On the formation of a new arsenal of scientific methodology of legal research in the field of nanotechnology and nano industry]. Vestnik Permskogo universiteta. Yuridicheskie nauki, 2016, no. 2(32), pp. 133-143.

6. Kachalova A.V. Pravovye osobennosti zaklyucheniya dogovorov o predostavlenii sinditsirovannykh kreditov [Legal aspects of concluding contracts for syndicated loans]. Zakonodatelstvo, 2006, no. 2, pp. 75-83. 


\section{ВОПРОСЫ ЧАСТНОПРАВОВОГО РЕГУЛИРОВАНИЯ}

7. Popkova L.A. Dogovor sinditsirovannogo kredita: pravovaya priroda i soderzhanie [Syndicated Loan Agreement: the legal nature and content]. Zakony Rossii. Opyt. Analiz. Praktika, 2016, no. 2, pp. 69-74.

8. Proekt Federalnogo zakona "O vnesenii izmeneniy v glavu 42 chasti vtoroy Grazhdanskogo kodeksa Rossiyskoy Federatsii i otdelnye zakonodatelnye akty Rossiyskoy Federatsii" [Draft Federal Law "On Amendments to Chapter 42 of Part Two of the Civil Code of the Russian Federation and Certain Legislative Acts of the Russian Federation"]. Ofitsialnyy sayt Minekonomrazvitiya Rossii [Official Website of the Ministry of Economic Development of Russia]. Available at: http://economy.gov.ru/minec/activity/sections/ria/ anounce/20150604. (accessed Septmber 18, 2016).
9. Rasporyazhenie Pravitelstva RF “Ob utverzhdenii Strategii innovatsionnogo razvitiya Rossiyskoy Federatsii na period do 2020 goda" ot 8 dek. 2011 g. № 2227-r [Decree of Government of the Russian Federation "On approval of the Russian Federation Innovative Development Strategy for the period up to 2020" of December 8, 2011 no. 2227-p]. Sobranie zakonodatelstva RF, 2012, no. 1, art. 216.

10. Sapunkova A.I. Pravovoe regulirovanie sinditsirovannogo kreditovaniya $v$ mezhdunarodnom kommercheskom oborote: avtoref. dis. ... kand. yurid. nauk [Legal regulation of syndicated loans in the international commercial turnover. Cand. jurid. sci. abs. diss.]. Moscow, 2008. 32 p.

\section{Information About the Author}

Olesya P. Kazachenok, Candidate of Juridical Sciences, Associate Professor, Department of Civil and International Private Law, Volgograd State University, Base Department of the Southern Scientific Center of the Russian Academy of Sciences, Prosp. Universitetsky, 100, 400062 Volgograd, Russian Federation, kazachenok@yandex.ru, gimchp@volsu.ru.

\section{Информация об авторе}

Олеся Павловна Казаченок, кандидат юридических наук, доцент кафедры гражданского и международного частного права, Волгоградский государственный университет, базовая кафедра ЮНЦ РАН, просп. Университетский, 100, 400062 г. Волгоград, Российская Федерация, o.kazachenok@yandex.ru, gimchp@volsu.ru. 